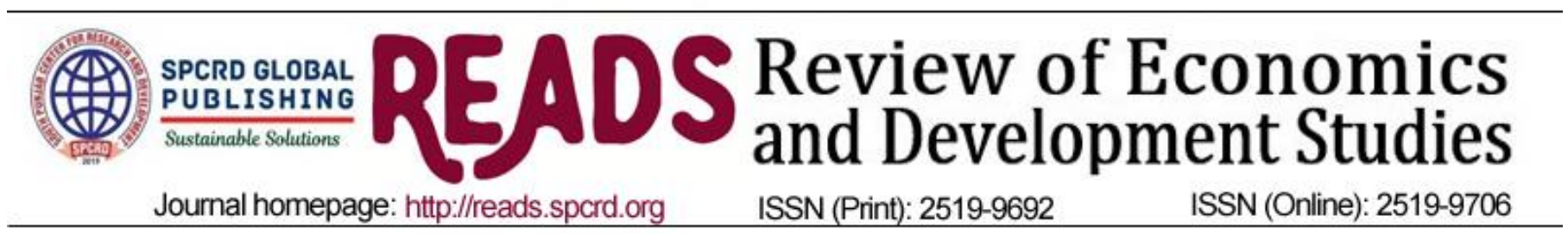

\title{
Feedback Impact in High, Average and Low Achievers' Mathematics Engagement in High Schools' Classrooms
}

\author{
a Tahira Batool \\ a Assistant Professor, Research and Evaluation Department, Lahore College for Women University, Lahore.
}

\begin{tabular}{l}
\hline ARTICLE DETAILS \\
\hline History: \\
Accepted 26 March 2020 \\
Available Online 31 March 2020
\end{tabular}

Keywords:

Feedback, Cognitive Engagement, Affective Engagement, Behavioral Engagement, High Achievers, Average Achievers, Low Achievers

JEL Classification: A21, A22, $C 65$

DOI: $10.47067 /$ reads.v6i1.194

\begin{abstract}
The present study has interrogated the effect of feedback on different ability groups' engagement in mathematics. The sample of this quasiexperimental research study was consisted of 87 grade nine students. The control group was consisted of 43 students whereas experimental group has total 44 students. Some feedback techniques and strategies were used in teaching during intervention. Students' engagement (cognitive, affective and behavioral) was measured by administering a questionnaire at the start and end of the intervention. Results has shown that intervention has a noteworthy effect on average and low achievers cognitive engagement but it has no significant effect in case of high achievers cognitive engagement. Results also have shown that intervention has significant effect on high, average and low achievers' affective engagement. Similarly, intervention has a noteworthy effect on of high achievers, average achievers and low achievers' behavioral engagement. Students in experimental group who were more engaged and spent more time on homework and extra work. These results highlighted the importance of feedback in mathematics classroom therefore further research on components of engagement is required.
\end{abstract}

(C) 2020 The authors. Published by SPCRD Global Publishing. This is an open access article under the Creative Commons Attribution-

NonCommercial 4.0

Corresponding author's email address: tahirashehbaz@yahoo.com

\section{Introduction}

Feedback is very important in assessment and is vital in helping students to learn from assessment (Irons, 2008). Therefore, teachers should be aware that positive dialogues are helpful in learning. Kaplan, Peck and Kaplan (1997) has shown that there is a downward relationship between students' poor academic performance and disengagement in which less engaged students' performance was found poor. So, the feedback has positive effect on students' achievement, but, the point to be explained is that which ability group of students is more beneficiary from feedback techniques (e.g. Batool \& Akhtar, 2019). As, Ali and Iqbal (2013) have used feedback as an important component of formative assessment in their study and have has also recommend to find out the difference of effect on different ability students' achievement in science. 


\section{Review of Economics and Development Studies, Vol. 6 (1) 2020, $\quad 167-178$}

The main objective of this study was to explore the effect of feedback on high, medium and low achievers engagement in mathematics. It was focused on finding out the effect of feedback on high, average and low achievers' cognitive engagement in mathematics. Similarly, comparison of affective and behavioral engagement of the average, high and low achievers of the experiment and the control groups in mathematics classroom was also point of investigation in this study. Researcher has tried to find out a comparison of time spent on homework and extra work of both control and experiment group.

\section{Literature Review}

Feedback has an important role in improvement of mathematics achievement. Research studies support this claim that feedback has significant effect on students' performance (e.g., Batool \& Akhtar, 2019; Mory, 2004; Narciss \& Huth, 2003). Though, other studies on feedback have shown no effect on performance (e.g., Kluger \& DeNisi, 1996; Fyfe, Rittle-Johnson, \& DeCaro, 2012). Ali and Iqbal (2013) have used feedback as an important component of formative assessment in their study and have shown its significant effect on students' achievement in science. They further told that formative assessment has more effect on high achievers and low achievers than medium ability students.

There was a positive relationship between classroom environment and the level of students' engagement (White \& Salovey, 2012). Kearney, Webb, Goldhorn and Peters (2013) has indicated in a multi-level analysis that when teachers provide critical feedback to the students' mathematics assignments they have higher level of learner engagement as compare to those classes where teachers did not give same feedback to their students. According to Kaplan, Peck and Kaplan (1997) there is a downward rise association between students' poor academic performance and disengagement in which less engaged students perform poorly. A research conducted by Kearney, Webb, Goldhorn and Peters (2013) has also mentioned that students engaged in one class have same attitude with other classes, they further showed that critical feedback in the form of discussion plays important role in determining the level of students' engagement. They said that when students are provided with feedback slowly, they are more engaged in their mathematics classes. Bert (2011) has discussed that give chance to the student to show their competence by demonstration, let them come to the whiteboards and show their competencies. Bert explained that these activities performed on the white board should be controlled by the teacher to engage students. Kedwell (2010), has discussed that persuasive writing, organized debates and problem based learning can increase the level of students' engagement. Similarly, peer relationship also matters, like when students feel uncomfortable with their social group. Researchers' indication have shown high level of achievement does not ensure high level of mathematics engagement. They have further shown that despite of learners' relative success in mathematics they were disengaged from mathematics and t. So, there is a need to understand the reason and degree of engagement required for high achievers (Skilling, Bobis, \& Martin; 2015). Whereas, the engagement in mathematics is an influencing factor in mathematics and the relationship between engagement and achievement needs further explanations to support students' engagement in mathematics (McPhan, Morony, Pegg, Cooksey, \& Lynch; 2008). The researchers have noted that influencing factors like interest participation and achievement in Mathematics decline as student transfer from primary to lower secondary school level (McPhan, Morony, Pegg, Cooksey, \& Lynch; 2008).

Engagement is defined as a multi-dimensional construct. Researchers have proposed that students' engagement in education includes three main areas: cognitive, emotional and behavioral (Connell, 1990; Connell \& Wellborn, 1991; Fredricks, Blumenfeld, \& Paris, 2004; Kong, Wong, \& Lam, 2003).Cognitive engagement comprises on deal with learning and a readiness to go further than the basic requirements to master problematic skills. Cognitive engagement researchers have explored 


\section{Review of Economics and Development Studies, Vol. 6 (1) 2020, $\quad 167-178$}

learning as a key indicator of overall investment in learning (Fredricks, Blumenfeld, \& Paris, 2004). Behavioral engagement comprises on the students' level of involvement in the school activities and the contribution in educational learning tasks, positive manner and the absence of disturbing behaviors (Fredricks, Blumenfeld, \& Paris, 2004). Both academic and nonacademic school behaviors are included behavioral engagement and have effect on academic achievement. Behavioral engagement can be perceived as students' positive conduct. For example, following the class rules in the classroom and showing a lack of troublesome behavior (Finn, 1993). Researchers have shown that positive behavior as completion of homework and obeying school rules are indicators of behavioral engagement. According to psychological and educational researchers affective engagement includes students and teachers relationships, it consists of students' emotional responses that include interest and anxiety (Russell, Ainley, \& Frydenberg, 2005). Affective engagement also includes emotions which are experienced by students such as frustrations, anxiety, attitude, interest, boredom, involvement, expectations and a sense of belonging (Kong, Wong, \& Lam, 2003). There is a need for conducting the studies on components of engagement and different ability group mathematics achievement. The main objective of the study is to explore the effect of feedback on high achievers, medium achievers and low achievers engagement in mathematics.

Following null hypotheses are formulated to address above questions:

Ho1: There is no noteworthy effect of feedback on high, average and low achievers' cognitive engagement in mathematics.

Ho2: There is no noteworthy effect of feedback on high, average and low achievers' affective engagement in mathematics.

Ho3: There is no noteworthy effect of feedback on high, average and low achievers' behavioral engagement in mathematics.

Ho4: There is no comparative difference in means of students' time spent on homework and extra work of control and experiment group

\section{Methodology}

\subsection{Research Design}

A quantitative research method was used in this study. Researcher has used experimental method followed a quasi-experimental design. This design is also called matching-only pretest posttest control group design. Four chapters from text book of grade nine were selected for this study. The experiment was continued for 16 weeks.

\subsection{Sample}

Convenient sampling technique was used and eighty six nine graders were selected to conduct this research. Two intact classes of grade IX students of mathematics from the conveniently selected school were taken as the sample of the study. One section with 44 students was decided as an experiment group by using random assignment technique and similarly other section on with 43 students as a control group. Researcher matched the groups on one variable that was students' results in the subject of Mathematics in grade VIII to find the equivalence of both groups. Control group was divided into three ability groups and same for experiment groups (groups were named as high achiever, average achiever and low achiever).

\subsection{Procedure}

Feedback was given to the experiment group and no feedback to control group. Feedback was given on students' in-class work, independent practice assignments, daily homework and teacher's 
discussion with a student, a group of students or whole class. While control group was taught by routine methods that was already tradition in their class. Sometimes feedback got the form of dialogic feedback.

The Planned feedback and Interactive feedback were main techniques of feedback used in this intervention. Feedback was given before starting the lesson, in the middle and when the lesson was at the end of lesson in the form of discussion, written comment or verbal work. At the start of the lesson, feedback was given when teacher was using questions to know about students' previous knowledge to start a new lesson, in case of any misconception or misunderstanding appropriate feedback was given.

Similarly, in the middle of the lesson when teacher's objective was to check students' understanding about the concept taught, researcher gave them some written work in the form of problem solving techniques or discussion. If there was difficulty with understanding some concept, researcher gave them feedback in the form of written comments or verbal corrections or dialogues to facilitate them and involve them in thinking process so that they can got true meaning of the under consideration concept.

However, feedback that was planned in advance, was not only planned for collecting information about students' learning, rather it was introduced so as to engage students in mathematical concepts. It was also in the form of verbal or written comments on students' answer on white-board or notebooks. Students were asked to answer the question with think pair-share technique, they were asked to discuss or consult with their peer. After giving students some time for thinking, researcher was preceded for further question. This type of feedback was depending upon students' response.

The interactive or informal feedback took place when the teacher was interacting with a student, group of students or the whole class. Questioning was the main instrument for such feedback. The response of the student to the question enabled the researcher to decide what to do next: whether to extend discussion or question answer session or give appropriate feedback to guide the student towards correct answer. As it was built on the students' response which cannot be anticipated, therefore, the teacher kept on switching from formal to informal and informal to formal feedback.

Researcher has assigned homework in the form of daily homework and independent practice assignments to the students, to write answers to the given questions. Instead of telling students about right or wrong answer, possible solution to the question were given on note books in case of home work. Independent practice assignments were given at the end of each chapter. Grades were given to the independent practice assignments by using grading rubrics. Researcher observed all mistakes and misunderstandings in the assignments and gave appropriate feedback through discussions and written explanations according to the need in class.

Occasionally, the technique of peer assessment was also used. In this technique students got grades or comments leading to correct answer from their peers. The marked answer sheet was back to the relevant students.

As researcher gave planned and unplanned feedback in order to enhance students' engagement in mathematics, it will be quite inevitable to check the effect of feedback techniques on students' engagement in mathematics. Therefore, researcher administered a questionnaire (Students Engagement in Mathematics) to the students of both the experiment group and the control group at the end of the intervention. 


\section{Results}

The results obtained in this study are shown in tables.

Table 1 Comparative Cognitive Engagement of the High, Average and Low Achiever in Mathematics Classroom

\begin{tabular}{|l|l|l|l|l|l|l|}
\hline & \multicolumn{2}{l|l}{ Control group } & \multicolumn{2}{l|}{$\begin{array}{l}\text { Experiment } \\
\text { group }\end{array}$} & & \\
\hline & $\mathrm{M}$ & $\mathrm{SD}$ & $\mathrm{M}$ & $\mathrm{SD}$ & $\mathrm{t}$ & $\begin{array}{l}\text { p (two- } \\
\text { tailed) }\end{array}$ \\
\hline High achievers cognitive eng (pretest) & 3.44 & 0.28 & 3.22 & 0.25 & 1.573 & .138 \\
\hline High achievers cognitive eng (posttest) & 3.44 & 0.16 & 3.42 & 0.11 & 0.522 & .613 \\
\hline Average achievers cognitive eng (pretest) & 3.39 & 0.41 & 3.25 & 0.31 & 1.413 & .162 \\
\hline Average achievers cognitive eng(posttest) & 3.34 & 0.38 & 3.65 & 0.12 & -1.780 & .141 \\
\hline Low achievers cognitive eng (pretest) & 3.32 & 0.16 & 3.17 & 0.33 & 1.155 & .270 \\
\hline Low achievers cognitive eng (posttest) & 3.22 & 0.24 & 3.41 & 0.28 & 1.712 & .033 \\
\hline
\end{tabular}

eng $=$ engagement, $\mathrm{df}($ high $\&$ low achievers $)=14, \mathrm{df}$ (average achievers) $=53,{ }^{*} \mathrm{p}<.05,{ }^{* *} \mathrm{p}<.01$

An independent samples t-test was conducted to compare the students' cognitive engagement scores in mathematics classroom in pretest of control and experiment group high achievers. Results revealed that that there is insignificant difference between the mean gain in cognitive engagement of experimental group (Mean =3.22) and control group (Mean =3.44) having t-value (1.573) and p =.138. The mean difference (0.21) analyzed in students' cognitive engagement in control and experiment group was minor. It indicates that students in experiment group have no higher gain in cognitive engagement as compare to the students' gain in cognitive engagement in control group. Therefore, initially (in pretest) both groups have high achievers with same cognitive engagement. Similarly, an independent samples t-test was conducted to compare the students' cognitive engagement scores in mathematics classroom in posttest of control and experiment group high achievers. Results revealed that there is no noteworthy difference between the mean gain in participants' cognitive engagement scores of experiment group (Mean =3.42) and control group (Mean =3.44) having t value (0.522) and $\mathrm{p}$ $=.613$. The mean difference (0.04) among students' cognitive engagement scores in posttest of control and experiment group was small. It indicates that students in experiment group have no higher gain in cognitive engagement as compare to the students' gain in cognitive engagement in control group. Therefore, intervention did not significantly effect on cognitive engagement of high achievers in experiment group.

An independent samples t-test was conducted to compare the students' cognitive engagement in mathematics classroom in pretest of control and experiment group average achievers. Results revealed that there is no noteworthy difference among the mean gain in cognitive engagement of experiment group (Mean =3.25) and control group (Mean =3.39) having t value 1.413 and $\mathrm{p}=.162$. The mean difference (0.14) between students' cognitive engagement in pretest of control and experiment group was small. It directs that average achievers in experiment group have no higher gain in cognitive engagement as compare to the average achievers' gain in cognitive engagement in control group. Therefore, initially (in pretest) both groups have average achievers with same cognitive engagement. 
Likewise, an independent samples t-test was conducted to compare the students' cognitive engagement in mathematics classroom in posttest of control group and experiment group average achievers. Results revealed that there is no important difference among the mean gain in cognitive engagement of experiment group (Mean =3.65) and control group (Mean =3.34) having t value $(-1.78)$ and $\mathrm{p}=0.141$. The mean difference (-0.31) in students' cognitive engagement in pretest of control and experiment group was medium. The eta squared value (.o6) has moderate effect size. It designates that average achievers in experiment group have higher gain in cognitive engagement as compare to the average achievers' gain in cognitive engagement in control group. Therefore, intervention has a reasonable effect on cognitive engagement of average achievers in experiment group.

An independent samples t-test was conducted to compare the participants' cognitive engagement in mathematics classroom in pretest of control group and experiment group low achievers. Results revealed that there is no noteworthy difference among the mean gain in cognitive engagement of experiment group (Mean =3.17) and control group (Mean =3.32) with t value (1.15) and $\mathrm{p}=.270$. The mean difference (0.15) among cognitive engagement in pretest of control and experiment group students was small. It indicates that low achievers in experiment group have no higher gain in cognitive engagement as compare to the low achievers' gain in cognitive engagement in control group. Therefore, initially (in pretest) both groups have low achievers with same cognitive engagement. Similarly, an independent samples t-test was conducted to see difference of students' cognitive engagement in mathematics classroom in posttest of control group and experiment group low achievers. Results exposed that there is a significant difference between the mean gain in cognitive engagement of experiment group (Mean =3.41) and control group (Mean =3.22) with t value $(1.71)$ and $\mathrm{p}=.033$. The mean difference (-0.19) among cognitive engagement scores in pretest of control and experiment group was significant. The eta squared value (.17) has greater effect size. It designates that low achievers in experiment group have considerably higher increase in cognitive engagement as compare to the low achievers' gain in cognitive engagement in control group. Therefore, intervention has a significant effect on cognitive engagement of low achievers in experiment group.

Table 2 Comparative Affective Engagement of the High Achiever, Average Achiever and Low Achiever in Mathematics Classroom

\begin{tabular}{|l|l|l|l|l|l|l|}
\hline & \multicolumn{2}{l|}{ Control group } & \multicolumn{2}{l|}{$\begin{array}{l}\text { Experiment } \\
\text { group }\end{array}$} & & \\
\hline & M & SD & M & SD & t & $\begin{array}{l}\text { p (two- } \\
\text { tailed) }\end{array}$ \\
\hline High achievers affective eng (pretest) & 3.36 & 0.33 & 3.45 & 0.35 & -0.49 & .629 \\
\hline High achievers affective eng (posttest) & 3.56 & 0.18 & 3.03 & 0.27 & 4.592 & $<.001$ \\
\hline Average achievers affective eng (pretest) & 3.54 & 0.36 & 3.45 & 0.25 & 1.113 & .270 \\
\hline Average achievers affective eng (posttest) & 3.48 & 0.23 & 3.05 & 0.28 & 5.962 & $<.001$ \\
\hline Low achievers affective eng (pretest) & 3.53 & 0.14 & 3.39 & 0.21 & 1.680 & .121 \\
\hline Low achievers affective eng (posttest) & 3.49 & 0.26 & 3.15 & 0.20 & 3.121 & $<.001$ \\
\hline
\end{tabular}

eng = engagement, $\mathrm{df}($ high\& low achievers $)=14$, df(average achievers $)=53$

An independent samples t-test was applied to see difference of the students' affective engagement in mathematics classroom (pretest) of control group and experiment group high achievers. Results revealed no noteworthy difference among the mean gain in affective engagement of experiment group (Mean =3.45) and control group (Mean =3.36) with $t(14)=-0.49$ and $p=.629$. The difference of mean (- o.09) in participants' affective engagement among pretest scores of control and experiment group was smaller. It indicates that students in experiment group have no higher gain in affective 


\section{Review of Economics and Development Studies, Vol. 6 (1) 2020, $\quad 167-178$}

engagement as compare to the students' gain in affective engagement in control group. Therefore, in pretest of participants both experiment and control groups have high achievers with same affective engagement. Similarly, an independent samples t-test was applied to see difference of the students' affective engagement in mathematics classroom in posttest conducted in control group and experiment group high achievers. Results revealed a noteworthy difference among the mean gain in affective engagement of experiment group (Mean =3.03) and control group (Mean =3.56) having t value $(4.59)$ and $\mathrm{p}<.001$. The mean difference (0.53) analyzed among students' affective engagement scores in posttest of control and experiment group was greater. The eta squared value (.60) has greater effect size. It indicates that students in experiment group have higher gain in affective engagement as compare to the students' gain in affective engagement in control group. Therefore, intervention has a significant effect on affective engagement of high achievers in experiment group.

An independent samples t-test was conducted to see difference of the students' affective engagement in mathematics classroom in pretest conducted in control group and experiment group average achievers. Results revealed insignificant difference between the mean gain in affective engagement of experiment group (Mean =3.45) and control group (Mean =3.54) having t value (1.11) and $\mathrm{p}=.270$. The mean difference (- o.o9) analyzed among students' scores of affective engagement in posttest of control and experiment group was small. It indicates that students in experiment group have no higher gain in affective engagement as compare to the students' gain in affective engagement in control group. Therefore, initially (in pretest) both groups have average achievers with same affective engagement. In the same way, an independent samples t-test was conducted to see difference of the students' affective engagement in mathematics classroom in posttest of control group and experiment group average achievers. Results revealed that there is a significant difference between the mean gain in affective engagement of experiment group (Mean =3.05) and control group (Mean =3.54) having $t$ value (5.96) and $\mathrm{p}<.001$. The mean difference (0.42) among affective engagement in posttest of control and experiment group students was large. The eta squared value (.40) has greater effect size. It indicates that students in experiment group have higher gain in affective engagement as compare to the students' gain in affective engagement in control group. Therefore, intervention has a significant effect on affective engagement of average achievers in experiment group.

An independent samples t-test was conducted to compare the students' affective engagement in mathematics classroom in pretest of control group and experiment group low achievers. Results revealed in analysis of scores in above table having $\mathrm{t}(14)=1.68, \mathrm{p}=.121$ shows that there is no significant difference between the mean gain in affective engagement of experiment group (Mean =3.39) and control group (Mean =3.53). The mean difference (0.14) among control and experiment group students' affective engagement was small. It indicates that students in experiment group have no higher gain in affective engagement as compare to the students' gain in affective engagement in control group. Therefore, initially (in pretest) both groups have low achievers with same affective engagement. Similarly, an independent samples t-test was conducted to compare the students' affective engagement in mathematics classroom (in posttest) in control group and experiment group low achievers. Results revealed in analysis of scores in above table having $\mathrm{t}(14)=3.12, \mathrm{p}<.001$ shows that there is a significant difference between the mean gain in affective engagement of experiment group (Mean =3.15) and control group (Mean =3.49). The mean difference (0.39) among affective engagement of control and experiment group students was large. The eta squared value (.39) has large effect size. It indicates that students in experiment group have higher gain in affective engagement as compare to the students' gain in affective engagement in control group. Therefore, intervention has a significant effect on affective engagement of low achievers in experiment group. 


\section{Review of Economics and Development Studies, Vol. 6 (1) 2020, $\quad 167-178$}

An independent samples t-test was conducted to see difference the students' behavioral engagement in mathematics classroom in pretest conducted in control group and experiment group high achievers. Results revealed in analysis of scores in above table 3 having t (14) $=-0.67, \mathrm{p}=.512$ shows that there is insignificant difference among the mean gain in behavioral engagement of experiment group (Mean $=2.43$ ) and control group (Mean $=2.17$ ). The mean difference $(-0.27)$ between control and experiment group students was small. It indicates that students in experiment group have no higher gain in behavioral engagement as compare to the students' gain in behavioral engagement in control group. Therefore, initially (in pretest) both groups have high achievers with same behavioral engagement. Likewise, an independent samples t-test was conducted to compare the students' behavioral engagement in mathematics classroom in posttest of control group and experiment group high achievers. Results revealed in analysis of scores in above table having $\mathrm{t}(14)=-4.15, \mathrm{p}<.001$ shows that there is a significant difference between the mean gain in behavioral engagement of students of experiment group (Mean =4.02) and control group (Mean =2.67). The mean difference (1.35) in students' behavioral engagement in control and experiment group was large. The eta squared value (.51) has greater effect size. It indicates that students in experiment group have higher gain in behavioral engagement in comparison with the students' gain in behavioral engagement in control group. Therefore, intervention has a significant effect on behavioral engagement of high achievers in experiment group.

Table 3 Comparative Behavioral Engagement of the High Achiever, Average Achiever and Low Achiever in Mathematics Classroom

\begin{tabular}{|l|l|l|l|l|l|l|}
\hline & \multicolumn{2}{l}{ Control group } & \multicolumn{2}{l|}{$\begin{array}{l}\text { Experiment } \\
\text { group }\end{array}$} & & \\
\hline & M & SD & M & SD & t & $\begin{array}{l}\text { p (two- } \\
\text { tailed) }\end{array}$ \\
\hline High achievers behavioral eng (pretest) & 2.17 & 0.68 & 2.43 & 0.89 & -.673 & .512 \\
\hline High achievers behavioral eng (posttest) & 2.67 & 0.76 & 4.02 & 0.48 & -4.155 & $<.001$ \\
\hline Average achievers behavioral eng (pretest) & 2.22 & 0.56 & 2.14 & 0.50 & 0.605 & .552 \\
\hline Average achievers behavioral eng(posttest) & 2.30 & 0.60 & 4.17 & 0.37 & -13.88 & $<.001$ \\
\hline Low achievers behavioral eng (pretest) & 2.05 & 0.29 & 2.10 & 0.26 & -0.381 & .711 \\
\hline Low achievers behavioral eng (posttest) & 2.13 & 0.34 & 4.28 & 0.24 & -14.51 & $<.001$ \\
\hline
\end{tabular}

eng $=$ engagement, $\mathrm{df}($ high\& low achievers $)=14, \mathrm{df}$ (average achievers) $=53$,

An independent samples t-test was conducted to see difference of the students' behavioral engagement in mathematics classroom in pretest of control group and experiment group average achievers. Results revealed in analysis of scores in above table having t (53) $=0.60, p=.552$ shows that there is no noteworthy difference among the mean gain in behavioral engagement of experiment group (Mean =2.14) and control group (Mean = 2.22). The mean difference $(-0.09)$ analyzed in students' behavioral engagement among control and experiment group was small. It indicates that students in experiment group have no higher gain in behavioral engagement as compare to the students' gain in behavioral engagement in control group. Therefore, initially (in pretest) both groups have average achievers with same behavioral engagement. Similarly, an independent samples t-test was conducted to see difference the students' behavioral engagement in mathematics classroom in posttest of control group and experiment group average achievers. Results revealed in analysis of scores in above table having $\mathrm{t}(53)=-13.89, \mathrm{p}<.001$ shows that there is a significant difference between the mean gain in behavioral engagement of experiment group (Mean =4.17) and control group (Mean =2.30). The mean difference (- 1.35) among control and experiment group students' behavioral engagement was large. 
The eta squared value (.70) has greater effect size. It indicates that students in experiment group have higher gain in behavioral engagement as compare to the students' gain in behavioral engagement in control group. Therefore, intervention has a significant effect on behavioral engagement of average achievers in experiment group.

An independent samples t-test was conducted to see difference of the students' behavioral engagement in mathematics classroom in pretest of control and experiment group low achievers. Results revealed in analysis of scores in above table having t (14) $=-0.38, \mathrm{p}=.711$ shows that there is insignificant difference between the mean gain in behavioral engagement of experiment group (Mean =2.10) and control group (Mean = 2.05). The mean difference (- 0.05) between control and experiment group students' behavioral engagement was minor. It designates that students in experiment group have no higher gain in behavioral engagement as compare to the students' gain in behavioral engagement in control group. Therefore, initially (in pretest) both groups have low achievers with same behavioral engagement. Likewise, an independent samples t-test was conducted to see difference of the students' behavioral engagement in mathematics classroom in posttest of control group and experiment group low achievers. Results revealed in analysis of scores in above table having t $(14)=-14.51, p<.001$ shows that there is a noteworthy difference among the mean gain in behavioral engagement of experiment group (Mean $=4.28$ ) and control group (Mean $=2.13$ ). The mean difference $(-14.51)$ among control and experiment group students behavioral engagement was significant. The eta squared value (.90) has great effect size. It indicates that students in experiment group have higher gain in behavioral engagement as compare to the students' gain in behavioral engagement in control group. Therefore, intervention has a significant effect on behavioral engagement of low achievers in experiment group.

Table 4 Comparison of Time Spent on Homework and Extra Work of control and experiment group

\begin{tabular}{|c|c|c|c|c|c|c|c|c|}
\hline & \multicolumn{4}{|c|}{ Control group } & \multicolumn{4}{|c|}{ Experiment group } \\
\hline & \multicolumn{2}{|c|}{$\begin{array}{l}\text { Time spend on } \\
\text { homework }\end{array}$} & \multicolumn{2}{|c|}{$\begin{array}{l}\text { Time spend on extra } \\
\text { work }\end{array}$} & \multicolumn{2}{|c|}{$\begin{array}{l}\text { Time spend on } \\
\text { homework }\end{array}$} & \multicolumn{2}{|c|}{$\begin{array}{l}\text { Time spend on extra } \\
\text { work }\end{array}$} \\
\hline & Pre test & Posttest & Pre test & Posttest & Pre test & Posttest & Pre test & Posttest \\
\hline $\mathrm{O}$ & 12 & 10 & 20 & 11 & 13 & 23 & 20 & 3 \\
\hline 1 & 20 & 18 & 11 & 8 & 20 & 10 & 9 & 4 \\
\hline 2 & 4 & 3 & 5 & 15 & 2 & 3 & 4 & 4 \\
\hline 3 & 2 & 4 & 2 & 10 & 3 & 3 & 4 & 17 \\
\hline 4 & 3 & 2 & 2 & & 4 & 2 & 3 & 13 \\
\hline 5 & 2 & 4 & 3 & 3 & 2 & 2 & 2 & 20 \\
\hline Mean & 0.77 & 0.73 & 0.64 & 0.68 & 0.59 & 3.55 & 0.86 & 4.43 \\
\hline SD & 0.61 & 0.59 & 1.12 & 1.17 & 0.50 & 1.11 & 1.28 & 0.66 \\
\hline
\end{tabular}

Results in table 4 revealed the time spent on homework and extra work at home. It indicates that mean score of time spent on homework is decreased in posttest of control group. On the other hand, time spent on homework is considerably increased in posttest of experiment group.

\section{Discussion}

This study was conducted to explore the feedback effects of three components of engagement (cognitive engagement, affective engagement and behavioral engagement) on three ability groups (high achievers, average achievers and low achievers). The findings of this research shows that students of each ability group have benefited from feedback which consequently resulted increase in students' engagement in mathematics classroom. So, feedback has positive role in teaching and learning process 
of each ability group (Batool \& Akhtar, 2019; Hattie \& Timperley, 2007).

Findings of this research has shown that when feedback techniques were used in mathematics classroom, high achievers' cognitive engagement as compared to other ability groups was less increased. Whereas, feedback has significant increase in cognitive engagement of both average achievers and low achievers cognitive engagement (e.g. Fung, Tan \& Chen, 2018; Fielding-Wells \& Makar, 2008; Kong \& Hoare, 2011). There is less literature on relationship of components of engagement on different ability groups separately. Therefore, there is still a need to explore these variables and their relationships)

In case of affective engagement, feedback has a significant effect on affective engagement of high achievers. Similarly, feedback has a significant effect on affective engagement of average achievers and low achievers in mathematics classroom.This finding has some identical features with previous researchers. Similarly, in case of behavioral engagement, feedback has a significant effect on behavioral engagement of high, average and low achievers in nine graders' mathematics classroom. Engagement may be boosted by some supportive environment (e.g. motivation and performance feedback) in high school classroom (Shernoff, Kelly, Tonks, Anderson, Cavanagh, Sinha \& Abdi, 2016).

This is an interesting finding of this study that students in classrooms with traditional teaching spent more time on extra work in the start of experiment. When feedback techniques were applied then students that were taught by using different techniques of feedback started to spent more time on extra work than other class (without feedback). So, feedback effect not performance in mathematics classroom but it has also helped students in engaging in activities and assignments at home. Researchers have done research on grade five to twelve have shown that teachers feedback on homework have indirect relationship with their academic achievement by effecting their behavior on mathematics. (Nunez, Suarez, Rosario, Vallejo, Cerezo \& Valle, 2015).

\section{Conclusion and Recommendations}

It is concluded from this study that feedback has significant effect on engagement of each ability group (High, average and low achievers). Data regarding each dimension of engagement (cognitive engagement, affective engagement and behavioral engagement) was collected two times during this study has shown significant difference in pretest and posttest of participants taught by using feedback techniques. It is shown that feedback has a significant effect on cognitive, affective and behavioral engagement of each ability group. Only, feedback given to high achievers has no significant effect on their cognitive engagement. This study has also indicated that time spent on extra work is considerably increased in posttest of experiment group. Therefore, feedback given to experiment group was also effective for homework and extra work done at home. So, students in experiment groups were not only performing well in mathematics classroom but they were engaged in activities and assignments at home also.

There is a need for conducting research on components of engagement separately. The study also recommend to conduct research on mathematics achievement of different ability group. The sample was consisting of the students of mathematics studying in grade nine but the same study should be conducted for the students of other subjects and grades also to find out the effect of feedback on students engagement.

\section{References}

Ali, I. \& Iqbal, M. H. (2013). Effect of formative assessment on students' achievement in science. World 
Applied Science Journal, 26(5), 67-687.

Balfanz, R., Fox, J. H., Bridgeland, J. M., \& McNaught, M. (2009). Grad Nation: A Guidebook to Help Communities Tackle the Dropout Crisis. America's Promise Alliance (NJ1).

Bardwell, R. (1981). Feedback: How does it function? The Journal of Experimental Education, 50(1), 4-9. Batool, T. \& Akhter, M. (2019). Feedback effects on secondary school students' achievement in Mathematics. Global Social Science Review, 4(3), 123-134.

Batool, T. (2018). Effect of feedback on students' engagement and achievement in mathematics in secondary schools. (Doctoral dissertation, University of the Punjab, Lahore, Pakistan).

Kearney, W. S., Webb, M., Goldhorn, J., \& Peters, M. L. (2013). Examining the impact of critical feedback on learner engagement in secondary Mathematics classrooms: a multi-level analysis. AASA Journal of Scholarship \& Practice, 10(1), 23-49.

Bert, C. (2011). Maximizing student engagement in the classroom. Milwaukee, WI: Moose Moss Press.

Black, P., \& Wiliam, D. (2009). Developing the theory of formative assessment. Educational Assessment, Evaluation and Accountability, 21(1), 5.

Chin, C. (2006). Classroom interaction in science: Teacher questioning and feedback to students' responses. International journal of science education, 28(11), 1315-1346.

Connell, J. P. (1990). Context, self and action: A motivational analysis of self-system process across the life-span. In D. Cricchetti \& M. Beeghly (Eds). The self in transition: From infancy to childhood (pp. 61-67). Chicago: Chicago University Press.

Connell, J. P., \& Wellborn, J. G. (1991). Competence, autonomy and relatedness: A motivational analysis of self-system processes. In M. Gunnar \& L. A. Sroufe (Eds.), Self-process in development: Minnesota Symposium on Child Psychology (Vol. 2, pp. 167-216).Hillsdale, NJ: Lawrence Erlbaum.

Cowie, B., \& Bell, B. (1999). A model of formative assessment in science education. Assessment in Education: Principles, Policy \& Practice, 6(1), 101-116.

Fielding-Wells, J., \& Makar, K. (2008, November). Student (dis) engagement in mathematics. In Annual Conference of the Australian Association for Research in Education, Brisbane, Australia.

Fredricks, J. A., Blumenfeld, P. C., \& Paris, A. H. (2004). School engagement: Potential of the concept, state of the evidence. Review of educational research, 74(1), 59-109.

Fung, F., Tan, C. Y., \& Chen, G. (2018). Student engagement and mathematics achievement: Unraveling main and interactive effects. Psychology in the Schools, 55(7), 815-831.

Fyfe, E. R., Rittle-Johnson, B., \& DeCaro, M. S. (2012). The effects of feedback during exploratory mathematics problem solving: Prior knowledge matters. Journal of Educational Psychology, 104(4), 1094.

Hattie, J., \& Timperley, H. (2007). The power of feedback. Review of educational research, 77(1), 81-112. Irons, A. (2007). Enhancing learning through formative assessment and feedback. Routledge.

Kaplan, D. S., Peck, B. M., \& Kaplan, H. B. (1997). Decomposing the academic failure-dropout relationship: A longitudinal analysis. The Journal of Educational Research, 9o(6), 331-343.

Kearney, S. W., Webb, M., Goldhorn, J., \& Peters,L., M.(2013). Examining the Impact of Critical Feedback on Learner Engagement in Secondary Mathematics Classrooms: A Multi-Level Analysis. Journal of Scholarship and Practice Vol. 10, No. 1

Kidwell, C. L. (2010). The impact of student engagement on learning. Leadership, 39(4), 28-31.

Kluger, A. N., \& DeNisi, A. (1996). The effects of feedback interventions on performance: A historical review, a meta-analysis, and a preliminary feedback intervention theory. Psychological Bulletin, 119(2), 254.

Kong, S., \& Hoare, P. (2011). Cognitive content engagement in content-based language teaching. Language Teaching Research, 15(3), 307-324.

Lowder, J. (2009). More than events: Focusing on student engagement and development. Campus 
Activities Programming, 41(7), 18-20.

McPhan, G., Morony, W., Pegg, J., Cooksey, R., \& Lynch, T. (2008). Maths? Why Not?. Canberra. Department of Education, Employment and Workplace Relations.

Mory, E. H. (2004). Feedback research revisited. Handbook of research on educational communications and technology, 2, 745-783.

Narciss, S., \& Huth, K. (2004). How to design informative tutoring feedback for multimedia learning. Instructional design for multimedia learning, 181195.

Nathan, M. J., \& Knuth, E. J. (2003). A study of whole classroom mathematical discourse and teacher change. Cognition and instruction, 21(2), 175-207.

Nicol, D., \& Macfarlane-Dick, D. (2004). Rethinking formative assessment in HE: a theoretical model and seven principles of good feedback practice. C. Juwah, D. Macfarlane-Dick, B. Matthew, D. Nicol, D. \& Smith, B.(2004) Enhancing student learning though effective formative feedback, York, The Higher Education Academy.

Nunez, J. C., Suarez, N., Rosario, P., Vallejo, G., Cerezo, R., \& Valle, A. (2015). Teachers' feedback on homework, homework-related behaviors, and academic achievement. The Journal of Educational research, 108(3), 204-216.

Orthner, D. K., Akos, P., Rose, R., Jones-Sanpei, H., Mercado, M., \& Woolley, M. E. (2010). CareerStart: A middle school student engagement and academic achievement program. Children \& Schools, 32(4), 223-234.

Peterson, K., \& Davis, B. H. (2008). A novice teacher improves student engagement through goal setting and literacy work stations. Ohio Journal of English Language Arts, 48(1), 17-23.

Portelli, J. P., \& Vibert, A. B. (2002). A curriculum of life. Education Canada, 42(2), 36-39.

Reyes, M. R., Brackett, M. A., Rivers, S. E., White, M., \& Salovey, P. (2012). Classroom emotional climate, student engagement, and academic achievement. Journal of educational psychology, 104(3), 700.

Russell, V. J., Ainley, M., \& Frydenberg, E. (2005). Student motivation and engagement. Schooling issues digest, 2, 1-11.

Schuster, S. (2011). Learner autonomy: A theoretical phantasm? International Journal of Learning, 18(4), 159-18o.

Shernoff, D. J., Kelly, S., Tonks, S. M., Anderson, B., Cavanagh, R. F., Sinha, S., \& Abdi, B. (2016). Student engagement as a function of environmental complexity in high school classrooms. Learning and Instruction, 43, 52-6o.

Shute, V. J. (2008). Focus on formative feedback. Review of educational research, 78(1), 153-189.

Skilling, K., Bobis, J., \& Martin, A. (2015, July). The engagement of students with high and low achievement levels in mathematics. In Proceedings of the 39th Psychology of Mathematics Education conference (Vol. 4, pp. 185-192). 